\title{
CHAK, NUEVO HÍBRIDO MEXICANO DE CACAO (Theobroma cacao L.) DE ALTO RENDIMIENTO Y CALIDAD
}

\author{
CHAK, A NEW HIGH-YIELD AND QUALITY MEXICAN COCOA \\ (Theobroma cacao L.) HYBRID
}

\begin{abstract}
Alfonso Azpeitia-Morales*
Instituto Nacional de Investigaciones Forestales, Agrícolas y Pecuarias, Campo Experimental Huimanguillo, Huimanguillo, Tabasco, México.

*Autor de correspondencia (azpeitia.alfonso@inifap.gob.mx)
\end{abstract}

En México las plantaciones de cacao (Theobroma cacao L.) ocupan una superficie de 58,467 ha con genotipos del tipo amelonado (70 \%), calabacillo (26\%) y criollo (4\%), los cuales se propagan por semilla. La producción nacional de grano de cacao seco es cercana a 28,363 t, con un rendimiento promedio de $485 \mathrm{~kg} \mathrm{ha}^{-1}$. En Tabasco existen 40,704 ha, donde se producen 18,275 t, y en Chiapas hay 17,518 ha que producen $9835 \mathrm{t}$ (SIAP, 2018). El rendimiento de cacao de ambas entidades es bajo, pues por ejemplo, el promedio de rendimiento en Ecuador, con la variedad CCN-

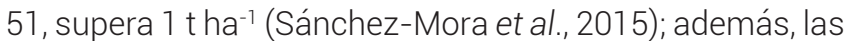
variedades mexicanas son susceptibles a enfermedades como la moniliasis (Moniliophthora roreri) y mancha negra (Phythophtora palmivora) (Barrón et al., 2014).

El cacao es un grano importante para elaborar chocolates y derivados; sin embargo, la producción no logra cubrir el mercado nacional actual. Con base en lo anterior, se proporciona información de una nueva variedad que representa una opción de calidad y rendimiento para el productor de cacao y chocolate en México.

El híbrido Chak se originó en el Campo Experimental Huimanguillo (CAEHUI), adscrito al Instituto Nacional de Investigaciones Forestales, Agrícolas y Pecuarias (INIFAP), en el estado de Tabasco. En 1995 se efectuó la cruza de los progenitores RIM 76A × EET48. El progenitor femenino corresponde a una selección clonal de un genotipo criollo de México y el masculino a una selección comercial clonal procedente del Ecuador (Escobar, 2008). El cruzamiento de estos progenitores originó una familia y su descendencia generó 30 plantas que se evaluaron a partir del año 1996 (híbridos $F_{1}$ ). Debido a la heterosis y heterogeneidad de los híbridos $F_{1}$, las evaluaciones posteriores fueron por individuo. En el año 2000 se seleccionaron individuos sobresalientes, los que se clonaron por injerto y se evaluaron en campo por aproximadamente 15 años; de esta manera se obtuvo el híbrido Chak, el cual se ha multiplicado clonalmente por injerto para mantener su identidad genética. La descripción varietal de este híbrido se basó en el manual de la UPOV (2011).

Las hojas son de limbo pequeño y de forma aguda, las hojas maduras son de color verde intenso y las hojas tiernas de color marrón, con ápice predominantemente agudo; su flor contiene un pedicelo con pigmentación antociánica fuerte, sépalos largos y anchos, lígulas de color amarillocrema, estaminodios con pigmentación moderada. El fruto es de gran tamaño y de forma obovada, con ápice agudo y de constricción basal débil, con superficie rugosa; los frutos jóvenes son de color violeta/verde y anaranjados al madurar (Figura 1). Las semillas contienen pulpa de color crema y de sabor agradable. El número de semillas es alto (40 semillas), de forma ovada y de gran tamaño. Sus cotiledones son de color rosa/violeta.

Las evaluaciones del rendimiento en plantas de 15 años indican que se pueden obtener hasta 35 frutos por árbol, libres de enfermedades, con un índice de fruto de 16; es decir, que con este número de frutos se produce un kilogramo de cacao seco. El testigo criollo regional presentó un índice de fruto de 30. El híbrido Chak presenta $84 \%$ de resistencia a la moniliasis en campo; en pruebas de inoculaciones directas mostró $80 \%$ de resistencia, mientras que el criollo regional presentó $50 \%$ de incidencia. La cata de grano de cacao seco fermentado y pasta de cacao presentó notas a cocoa, fruto fresco, frutos secos, nueces y floral. El conocimiento de caracteres organolépticos es importante, ya que pueden ser la distinción de una variedad para el consumidor; por ejemplo, el genotipo conocido como 'Nacional' de Ecuador, cuyo origen procede de la población Amazónica local y con cierta hibridación con tipos Trinitarios, se distingue por su especial aroma, con notas florales y de frutos secos (CAOBISCO/ECA/FCC, 2015). Los caracteres organolépticos del híbrido Chak son de interés comercial para elaborar chocolates exclusivos de esta nueva variedad, atributos que aún no se aprovechan en México.

El híbrido Chak está registrado en el Catálogo Nacional de 


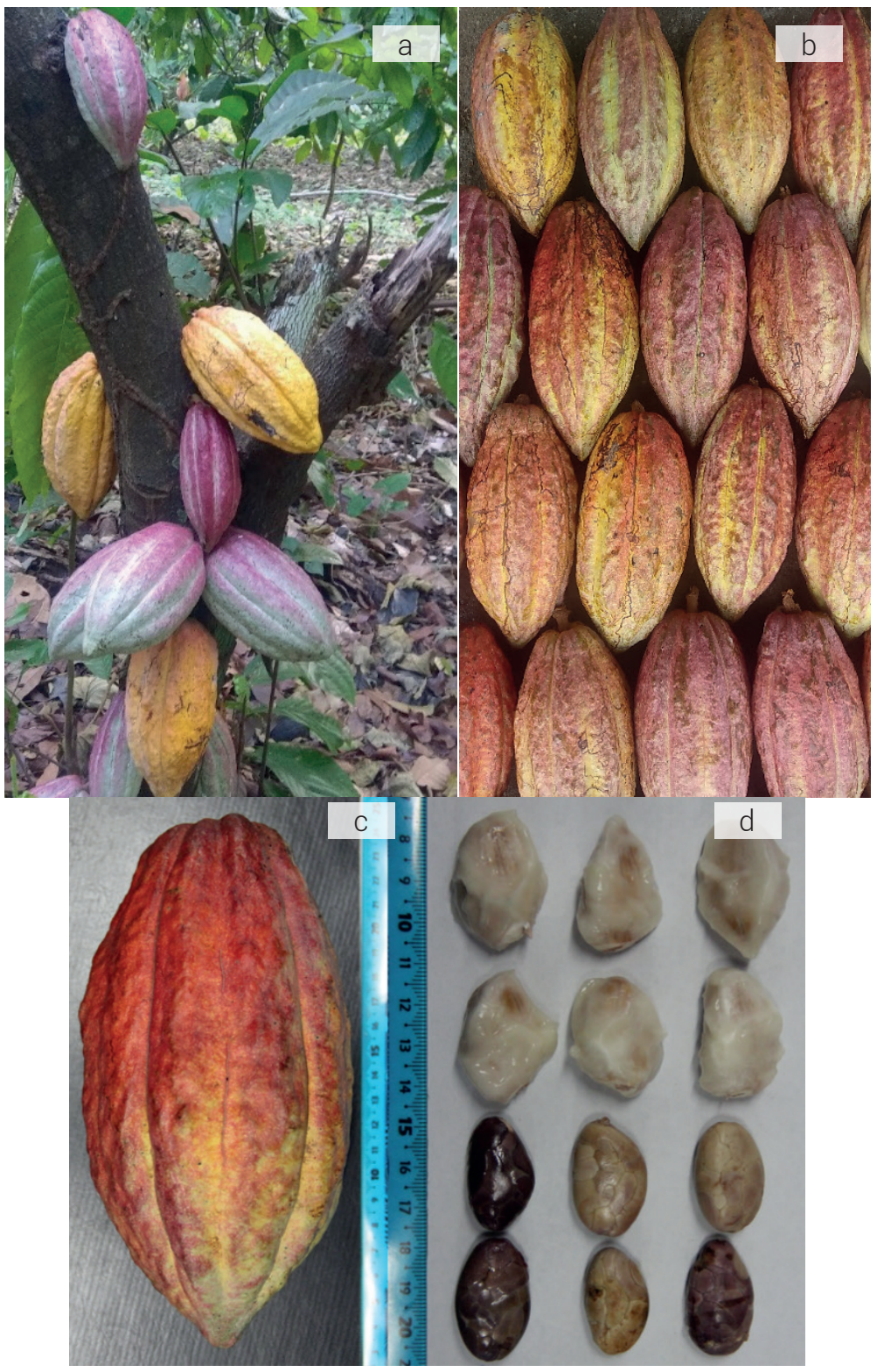

Figura 1. Árbol de cacao con frutos del híbrido Chak (a), aspecto de frutos maduros (b, c) y semillas con y sin mucílago (d).

Variedades Vegetales del Servicio Nacional de Inspección y Certificación de Semillas (SNICS) con el número CAO009-230218. El 3 de septiembre de 2019 se otorgó el título de obtentor Número 2269 por el Registro Nacional Agropecuario con vigencia al 3 de septiembre del año 2037. La multiplicación de esta variedad es asexual, por injerto, los cuales están a disposición de los cacaoteros del sur de México en el CAEHUI-INIFAP, en Huimanguillo, Tabasco.

\section{AGRADECIMIENTOS}

Al CONACYT, por el financiamiento parcial del proyecto número 1513 y al Museo del Chocolate de la Ciudad de México, a través de su directora Arq. Ana Rita García
Lascurain y al Chef José López Ganem, quienes dirigieron la cata de genotipos inéditos mexicanos.

\section{BIBLIOGRAFÍA}

Barrón G. Y. P., A. Azpeitia M., P. A. López A. y F. Mirafuentes-Hernández (2014) Metodología adaptada para la formación de híbridos F1 de cacao (Theobroma cacao L.) en Tabasco. Revista Mexicana de Ciencias Agrícolas 5:765-777, https://doi.org/10.29312/ remexca.v5i5.900

CAOBISCO/ECA/FCC, Chocolate, Biscuits \& Confectionery of Europe/European Cocoa Association/Federation of Cocoa Commerce (2015) Cocoa Beans: Chocolate and Cocoa Industry Quality Requirements. M.J. End and R. Dand (eds.). CAOBISCO/ECA/FCC. Brussels, Belgium and London, UK. $109 \mathrm{p}$.

Escobar R. (2008) Comportamiento de seis clones de "cacao" (Theobroma cacao L.) en Guasaganda, provincia de Cotopaxi, 
Ecuador. La Granja 7:9-12, https://doi.org/10.17163/lgr. n7.2008.02

Sánchez-Mora F. D., S. M. Medina-Jara, G. T. Díaz-Coronel, R. A. RamosRemache, J. F. Vera-Chang, V. F. Vásquez-Morán, ... y R. Onofre-Nodari (2015) Potencial sanitario y productivo de 12 clones de cacao en Ecuador. Revista Fitotecnia Mexicana 38:265-274

SIAP, Servicio de Información Agroalimentaria y Pesquera (2018) Anuario estadístico de la producción agrícola. Servicio de Información
Agroalimentaria y Pesquera, Secretaría de Agricultura y Desarrollo Rural. Ciudad de México. https://nube.siap.gob.mx/ cierreagricola/ (Mayo 2018)

UPOV, Unión Internacional para la Protección de las Obtenciones Vegetales (2011) Cacao Theobroma cacao L. Directrices para la ejecución del examen de la distinción, la homogeneidad y la estabilidad. TG/270/1. Unión Internacional para la Protección de las Obtenciones Vegetales. Ginebra, Suiza. 28 p. 
